\title{
PENGARUH PERUBAHAN POSISI DALAM MENCEGAH DEKUBITUS PADA PASIEN YANG MENJALANI PERAWATAN DI RUMAH SAKIT AMINAH CILEDUG TANGERANG
}

\author{
Adie Mulyadi Prawira Kusumah, Muhammad Taufik Daniel Hasibuan \\ Program Studi Ilmu Keperawatan, STIKes Murni Teguh \\ E-mail :adie.pkkep19@gmail.com; aniel.jibril@gmail.com
}

\begin{abstract}
Change of position is a position setting given to reduce friction on the skin so that it will reduce the chance of decubitus ulcers. This study aims to determine the effect of position changes in preventing pressure sores in patients undergoing treatment at Aminah Hospital Ciledug Tangerang. The population in this study were patients who were treated at Aminah Hospital Ciledug Tangerang and the sample studied was 44 people who were taken by using purposive sampling technique. The research method used is quasi-experimental, with a pre-test post-test with control group non randomization and data analysis using the Mann Whitney test. From the results of statistical tests using Mann Whitney, $\mathrm{p}$ value $=0.001$, this indicates that there is an effect of changing position in preventing decubitus. The results of this study are expected to be input and can be applied by health workers (nurses) in providing nursing care to patients who experience prolonged bed rest, and it is recommended at least every 2 hours.
\end{abstract}

Keywords: Change of Position, Decubitus

\begin{abstract}
Abstrak
Perubahan posisi merupakan pengaturan posisi yang diberikan untuk mengurangi gaya gesek pada kulit sehingga akan menurunkan peluang terjadinya luka dekubitus. Penelitian ini bertujuan untuk mengetahui pengaruh perubahan posisi dalam mencegah dekubitus pada pasien yang menjalani perawatan di Rumah Sakit Aminah Ciledug Tangerang. Populasi didalam penelitian ini adalah pasien yang di rawat di Rumah Sakit Aminah Ciledug Tangerang dan sempel yang diteliti sebanyak 44 orang yang diambil dengan cara menggunakan teknik Purposive sampling. Metode penelitian yang digunakan adalah Quasi experiment, dengan desain pre-test post-test with control group non randomization dan analisa data menggunakan uji Mann Whitney. Dari hasil uji statistik dengan menggunakan Mann Whitney di dapatkan p value $=0.001$, hal ini menunjukkan bahwa terdapat pengaruh dari perubahan posisi dalam mencegah decubitus. Hasil penelitian ini diharapkan menjadi masukan dan dapat diterapkan oleh petugas kesehatan (perawat) didalam pemberian asuhan keperawatan kepada pasien yang mengalami perawatan tirah baring yang lama, dan direkomendasikan minimal setiap 2 jam sekali.
\end{abstract}

Kata kunci: Perubahan Posisi, Dekubitus

\section{PENDAHULUAN}

Di Indonesia Sampai saat ini belum terdapat data pasti mengenai insiden luka dekubitus yang diterbitkan di Indonesia. Salah satu penelitian single center yang dilakukan oleh Suriadi et al. (2004) kejadian luka dekubitus di Pontianak pada tahun 2003 adalah $(33,3 \%)$. Studi lain dilakukan pada
1132 pasien di 4 rumah sakit di Indonesia melaporkan insiden terjadinya luka dekubitus sebesar (8\%) dengan kejadian terjadinya luka dekubitus sebelum masuk rumah sakit terjadi pada (44\%) pasien. Total dari luka dekubitus pada pasien tersebut adalah 142 luka dan (42\%) dari luka tersebut dikategorikan dalam luka dekubitus derajat 3 dan 4. Lokasi 
terjadinya luka dekubitus paling sering terjadi pada area sakrum, bokong dan tumit, (Amir, Lohrmann, Halfens, \& Schols, 2016). Hasil penelitian : menunjukkan bahwa dari 21 responden yang terbagi menjadi 11 responden kelompok intervensi 8 responden $(72,7 \%)$ dalam kategori kemungkinan kecil terjadi kejadian dekubitus dan 10 responden dalam kelompok kontrol 9 responden $(90 \%)$ berada di kategori kemungkinan terjadi dekubitus. Hasil uji statistik Mann Withney menunjukkan $p=0,001<\alpha=0,05$ maka H1 diterima. Maka hasil kesimpulan penelitian ini adalah ada pengaruh pemberian posisi Perubahan Posisi terhadap kejadian dekubitus pada pasien dengan kondisi berbaring di RSUD Jombang (Sari, 2018).

Rata-rata angka kejadian luka dekubitus yang ditemukan di sebuah Rumah Sakit di Tangerang yakni sebanyak 0,31\%, laporan angka kejadian luka dekubitusdi Siloam Hospitals Kebun Jerukdan Rumah Sakit di Jakarta pada tahun 2009 sebanyak $0,43 \%$. Sedangkan kejadian dekubitus di Rumah Sakit Aminah pada Januari-Juni 2020, jumlah kasus yang ditemukan di seluruh Ruang Rawat inap sebesar 3.1\%, sedangkan pada Unit ICU kejadian dekubitus sebesar 1.2\% (IPCN RS. Aminah 2020). Angka kejadian luka dekubitus ini masih belum sesuai dengan standar mutu pelayanan kesehatan yang ditetapkan WHO dan Depkes 2001 yakni 0\% (Lumenta, 2008 dalam Ivana, 2017).

Meskipun penelitian tentang prevalensi luka dekubitus bervariasi, dilaporkan bahwa secara umum 5-11\% dalam rangkaian perawatan akut, $15-25 \%$ dalam rangkaian perawatan jangka panjang, dan 7$12 \%$ dalam rangkaian perawatan di rumah. (Maryam, 2005).

Insiden luka dekubitus di rumah sakit lebih tinggi dibandingkan di komunitas seperti yang diungkapkan Hobbs (2004) pada perawatan jangka panjang seperti perawatan di rumah berkisar 2,4\%-23\%, sedangkan di rumah sakit 2,7\%-29,5\%. Hal ini cukup ironis, mengingat rumah sakit sebagai tatanan pelayanan rujukan dalam masalah kesehatan. Clark menyatakan bahwa teknologi yang semakin canggih, namun insiden luka dekubitus tidak pernah turun (Moore, 2004).

Pelaksanaan perubahan posisi merupakan salah satu peran perawat dalam pemberian pelayanan keperawatan, karena perawat merupakan salah satu anggota tim kesehatan yang berhubungan langsung dengan pasien selama 24 jam. Akan tetapi, pada kenyataannya masih ada beberapa perawat yang masih belum mengimplemen tasikan pelaksanaan perubahan posisi tersebut pada pasien-pasien dengan kondisi berbaring, serta pasien-pasien dengan faktor risiko dekubitus tinggi. Hasil penelitian yang telah dilakukan Wardani \& Widaryati (2019) bahwa responden yang melakukan tindakan perubahan posisi tiap 2 jam sebanyak 5 perawat yaitu $13.1 \%$ dari 38 responden. Berdasarkan distribusi frekuensi perilaku perawat dalam upaya pencegahan dekubitus dengan perilaku baik sebesar 26.3\%, berperilaku sedang sebesar $73.7 \%$.

Kasus luka dekubitus $95 \%$ dapat dicegah, fakta membuktikan bahwa tindakan pencegahan ini lebih efektif dan hemat biaya dari pada pengobatan (Maryam, 2005). Faktor internal yang menentukan kerentanan terhadap kerusakan jaringan antara lain malnutrisi, anemia, kehilangan sensasi, mobilitas, usia tua, penurunan status mental, inkontinensia urin, dan infeksi. Sedangkan faktor ekstrinsiknya adalah dekubitus, grafitasi dan gesekan. Adapun salah satu pencegahan munculnya luka dekubitus adalah Perubahan Posisi (Potter \& Perry, 2010).

\section{METODE PENELITIAN}

Jenis penelitian yang digunakan yaitu kuantitatif dengan design quasi experiment dan menggunakan metode pre-test post-test with control group non randomization. Penelitian ini membagi menjadi dua kelompok, yaitu : kelompok eksperimen dan kelompok kontrol. Dalam penelitian ini kelompok intervensi diberikan perlakuan yaitu perubahan posisi setiap 2 jam sekali, sedangkan kelompok kontrol tidak diberikan perlakuan atau berjalan seperti biasanya. Instrumen yang dipakai untuk menilai angka 
kejadian decubitus menggunakan skala Norton, dan analisis data untuk melihat pengaruh dari intervensi menggunakan Mann Withney. Penelitian ini dilakukan diruang Intensive Care Unit Rumah Sakit Aminah Ciledug Tangerang. Dilaksanakan pada bulan Maret sd April 2021.

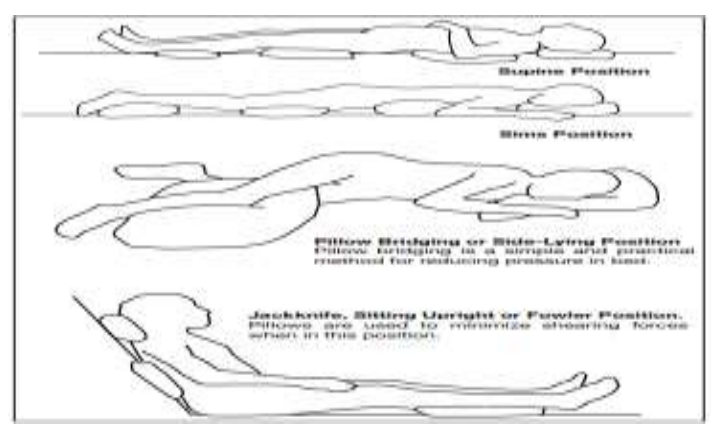

Gambar1.Posisi Tirah Baring Untuk Mencegah Dekubitus

HASIL PENELITIAN

Analisa Univariat

Tabel 1. Kejadian Dekubitus pada Kelompok intervensi pada WaktuPre-test

\begin{tabular}{lcc} 
Skor Skala Norton & Frekuensi & Presentase \\
\hline Tidak terjadi (TT) & 6 & $27.3 \%$ \\
\hline $\begin{array}{l}\text { Kemungkinan kecil } \\
\text { terjadi (KKT) }\end{array}$ & 12 & $54.5 \%$ \\
\hline $\begin{array}{l}\text { Kemungkinan besar } \\
\text { terjadi (KBT) }\end{array}$ & 4 & $18.2 \%$ \\
\hline \multicolumn{1}{c}{ Total } & 22 & $100 \%$ \\
\hline
\end{tabular}

Pada kelompok intervensi sebelum dilakukannya perlakuan di dapatkan persentase tertinggi dengan kriteria kemungkinan kecil terjadi sebanyak 12 dengan presentase (54.5\%), lalu dengan kriteria tidak terjadi sebanyak 6 dengan persentase (27.3\%).

Tabel 2. Kejadian Dekubitus pada Kelompok Kontrol pada WaktuPre-test

\begin{tabular}{lcc} 
Skor Skala Norton & Frekuensi & Presentase \\
\hline Tidak terjadi (TT) & 3 & $13.6 \%$ \\
\hline $\begin{array}{l}\text { Kemungkinan kecil } \\
\text { terjadi(KKT) }\end{array}$ & 9 & $40.9 \%$ \\
\hline $\begin{array}{l}\text { Kemungkinan besar } \\
\text { terjadi(KBT) }\end{array}$ & 10 & $45.5 \%$ \\
\hline \multicolumn{1}{c}{ Total } & 22 & $100 \%$ \\
\hline
\end{tabular}

Kelompok kontrol pada waktu pretest di dapatkan persentase tertinggi dengan kriteria kemungkinan besar terjadi sebanyak 10 dengan presentase (45.5\%), lalu dengan kriteria kemungkinan besar terjadi sebanyak 9 dengan persentase (40.9\%).

Tabel 3. Kejadian Dekubitus pada Kelompok intervensi pada Waktu Posttest

\begin{tabular}{lcc} 
Skor Skala Norton & Frekuensi & Presentase \\
\hline Tidak terjadi (TT) & 7 & $31.8 \%$ \\
\hline $\begin{array}{l}\text { Kemungkinan kecil } \\
\text { terjadi (KKT) }\end{array}$ & 11 & $50.0 \%$ \\
\hline $\begin{array}{l}\text { Kemungkinan besar } \\
\text { terjadi (KBT) }\end{array}$ & 4 & $18.2 \%$ \\
\hline \multicolumn{1}{c}{ Total } & 22 & $100 \%$ \\
\hline
\end{tabular}

Kelompok intervensi setelah dilakukan perlakuan di dapatkan persentase dengan kriteria tidak terjadi sebanyak 7 dengan presentase $(31.8 \%)$, dan kriteria kemungkinan kecil terjadi sebanyak 11 dengan persentase $(50 \%)$.

Tabel 4. Kejadian Dekubitus pada Kelompok Kontrol pada Waktu Post-test

\begin{tabular}{lcc} 
Skor Skala Norton & Frekuensi & Presentase \\
\hline Tidak terjadi (TT) & 2 & $9.1 \%$ \\
\hline $\begin{array}{l}\text { Kemungkinan kecil } \\
\text { terjadi (KKT) }\end{array}$ & 5 & $22.7 \%$ \\
\hline $\begin{array}{l}\text { Kemungkinan besar } \\
\text { terjadi (KBT) }\end{array}$ & 15 & $68.2 \%$ \\
\hline \multicolumn{1}{c}{ Total } & 22 & $100 \%$ \\
\hline
\end{tabular}

Kelompok kontrol setelah dilakukan observasi di dapatkan persentase tertinggi dengan kriteria kemungkinan besar terjadi sebanyak 15 dengan presentase $(68.2 \%)$, dan kriteria kemungkinan kecil terjadi sebanyak 5 dengan persentase $(22.7 \%)$

Tabel 5. Kejadian Luka Dekubitus pada Kelompok Intervensi

\begin{tabular}{lcc}
\hline Luka dekubitus & Frekuensi & Presentase \\
\hline Tidak luka & 21 & $95.5 \%$ \\
\hline Luka & 1 & $4.5 \%$ \\
\hline \multicolumn{1}{c}{ Total } & 22 & $100 \%$ \\
\hline
\end{tabular}


Tabel 6. Kejadian Luka Dekubitus pada Kelompok Kontrol

\begin{tabular}{ccc} 
Luka dekubitus & Frekuensi & Presentase \\
\hline Tidak luka & 19 & $86.4 \%$ \\
\hline Luka & 3 & $13.6 \%$ \\
\hline Total & 22 & $100 \%$ \\
\hline
\end{tabular}

Berdasarkan angka kejadian dekubitus pada kelompok eksperimen ditemukan sebanyak 1 responden mengalami luka dekubitus dengan persentase $4.5 \%$, sedangkan pada kelompok kontrol ditemukan sebanyak 3 responden mengalami luka dekubitus dengan persentase $13.6 \%$.

\section{Analisa Bivariat}

Tabel 7. Hasil Uji Statistik padaKelompok Post Intervensi dan Post Kontrol Menggunakan Mann Withney

\begin{tabular}{lllllll}
\multirow{2}{*}{$\begin{array}{l}\text { Perubahan } \\
\text { Posisi }\end{array}$} & \multicolumn{3}{c}{ Skor Skala Norton } & \multirow{2}{*}{ Total } & $\boldsymbol{p}$ \\
\cline { 2 - 4 } & TT & KKT & KBT & & \\
\hline Intervensi & $31.8 \%$ & $50 \%$ & $18.2 \%$ & $100 \%$ & 0.001 \\
\cline { 1 - 4 } Kontrol & $9.1 \%$ & $22.7 \%$ & $68.2 \%$ & $100 \%$ &
\end{tabular}

Bedasarkan hasil Uji Statistik Mann Withney test, didapatkan nilai $\mathrm{p}=$ 0,001 . Hasil tersebut lebih kecil dari taraf signifikan yang digunakan yaitu $\alpha=0,05$, maka dapat disimpulkan bahwa ada pengaruh pemberian perubahan posisi terhadap kejadian dekubitus pada pasien di Ruang Perawatan Rumah Sakit Aminah Ciledug Tangerang.

\section{PEMBAHASAN}

Bedasarkan hasil uji statistic MannWithney didapatkan nilai $p=0,001$. Hasil tersebut lebih kecil dari taraf signifikan yang digunakan yaitu $\alpha=0,05$, maka dapat disimpulkan bahwa ada pengaruh pemberian perubahan posisi terhadap kejadian dekubitus pada pasien di Ruang Perawatan Rumah Sakit Aminah Ciledug Tangerang.Penelitian ini sejalan dengan penelitian yang dilakukan oleh Sari (2018) pemberian posisi alih baring dengan kejadian dekubitus di dapatkan nilai $p$ $=0,001$ dengan kata lain ada pengaruh pemberian posisi alih baring terhadap kejadian decubitus.

Hasil penelitian Aini dan Heni (2013) menujukan bahwa pasien yang diberikan intervesi perubahan posisi tidak ada yang mengalami dekubitus, sedangkan pada kelompok yang tidak mendapatkan intervensi terdapat 8 pasien $(53,3 \%)$ yang mengalami dekubitus derajat 1. Berdasarkan penelitian ini membuktikan bahwa ada pengaruh alih baring terhadap kejadian dekubitus pada pasien yang mengalami perawatan di rumah sakit. Hal ini didukung oleh teori Sujarwo (2011) dalam Sari (2018) memposisikan pasien terlentang ke kiri dan ke kanan dalam waktu 2 jam sekali guna menghindari terjadinya kerusakan syaraf dan pembuluh darah, selain itu perubahan posisi dapat berguna untuk mempertahankan tonus otot dan reflex. Menurut Hutahaean dan Hasibuan (2020) penurunan kekuatan otot dapat disebabkan oleh kurangnya pergerakan atau aktifitas fisik.

\section{KESIMPULAN}

Berdasarkan hasil penelitian ini, maka peneliti menyimpulkan bahwa perubahan posisi memiliki manfaat dalam mencegah dekubitus pada pasien yang menjalani perawatan di rumah sakit, terutama pada pasien dengan rentang usia 41-60 tahun, dimana pada usia tersebut terjadi beberapa perubahan seperti menipisnya kulit, kehilangan jaringan lemak, menurunnya fungsi persepsi sensori, meningkatnya fragilitas pembuluh darah, dan lain sebagainya.

\section{SARAN}

Diharapkan petugas kesehatan yang merawat pasien dengan kondisi bed rest dapat lebih memperhatikan dalam pemberian perubahan posisi untuk mencegah terjadinya dekubitus dan memberikan edukasi kepada pihak keluarga untuk dapat dipahami dan diterapkan dalam memberikan perawatan pada keluarga yang sakit. 


\section{REFERENSI}

Aini, F, P., \& Heni. (2013). Pengaruh alih baring terhadap kejadian dekubitus pada pasien stroke yang mengalami hemiparesis diruang yudistira. Rsud semarang. Skripsi, Stikes Ngudi Waluyo. Semarang.

Amir, Y., Lohrmann, C., Halfens, RJG., \& Schols, JM. (2016). Pressure ulcers in four Indonesian hospitals : prevalence, patient characteristic, ulcer characteristic, prevention and treatment. Int Wound $J$ 2017; 14:184-193. doi: 10.1111/iwj.12580

Hobbs, B.K. (2004). Reducing the incidence of pressure ulcers; implementation of a turn-team nursing program. Journal of gerontological nursing, 30 (11): 46-51. Retrieved from www.aacn.org/wd/nti2009/nti_cd?da ta/papers/ , March 20, 2010.

Hutahaean, R. E., \& Hasibuan, M. T. D. (2020). Pengaruh range of motion terhadap kekuatan otot pada pasien stroke iskemik di rumah sakit umum HKBP Balige. Indonesian Trust Health Journal, 3(1), 278-282.

IPCN RS Aminah. (2020), Laporan Rekam Medik RS Aminah, Ciledug Kota Tangerang

Ivana, E. (2017). Gambaran peran perawat dalam pencegahan dekubitus di bangsal wijaya kusuma. RSUD Wates Kulon Progo. Skripsi, STIKes Jenderal Achmad Yani

Maryam.(2005). Ulkus dekubitus dalam Asuhan Keperawatan. Universitas Jendral Sudirman Purwokerto.

Moore, Z., Price, P. (2004). Nurse's attitude, behaviours and perceived barriers towards pressure ulcer prevention. Journal of clinical nursing Volume: 13 Page 942-951. Retrieved from http://www. ebscohost.com/uph.edu on February 13, 2010.

Potter, Perry. (2010). Fundamental of nursing: consep, proses and practice. Edisi 7.Vol. 3.Jakarta : EGC
Sari, E, N. (2018) Pengaruh pemberian posisi alih baring terhadap kejadian dekubitus pada pasien stroke di RSUD Jombang. Skripsi, STIKes Insan Cendikia Medika.

Suriadi.(2004). Perawatan luka. Edisi I. Jakarta : CV. Sagung Seto.

Wardani, A, S., \& Widaryati (2019). Hubungan motivasi dengan perilaku perawat dalam upaya pencegahan dekubitus. Skripsi, Faculty of Medicine, Health and Life Sciences : Study Program of Nursing. Universitas 'Aisyiyah Yogyakarta. 